\title{
Evidence-based alcohol policy in the Americas: strengths, weaknesses, and future challenges
}

\author{
Thomas F. Babor ${ }^{1}$ and Raul Caetano ${ }^{2}$
}

ABSTRACT The objectives of this article are to describe the evidence base for alcohol policy in the Americas, to evaluate the extent to which national policies are likely to have an impact on public health, and to identify areas where alcohol policies could be improved. The paper begins with a brief review of epidemiological surveys of the prevalence of alcohol problems in the Americas. This is followed by an analysis of 32 prevention strategies and interventions in terms of the evidence for their effectiveness, amount of research support, cost to implement, and other feasibility issues. Overall, the strategies and interventions with the greatest amount of empirical support are low blood alcohol concentration levels for driving while intoxicated, controls on alcohol availability, age limits on alcohol purchases, and relatively high alcohol prices. The implications of the evidence are next discussed in relation to alcohol policy initiatives in the Americas, based on an analysis of the extent to which strategies and interventions currently used in 25 countries of the Americas are likely to have a public health impact on alcoholrelated problems. The countries that have adopted the policies with the highest expected impact overall are Colombia, Costa Rica, Venezuela, and El Salvador. Nevertheless, the analysis indicates that almost all the countries of the Americas could improve the likelihood of preventing alcohol-related problems. Policy efforts in the developing countries of Latin America should focus on improving countermeasures against driving while intoxicated, measures that alter the drinking context, and limits on physical availability. For the developed, high-income countries of North America the goal should be to prevent deterioration of current drinking patterns and to reduce the overall volume of drinking. Given the low to moderate cost of many of the policies reviewed in this article, it now seems possible for communities and nations to substantially reduce the alcohol-related burden of illness in the Americas.

Key words Alcohol drinking, alcoholic intoxication, evidence-based medicine, policy making, Americas.

1 University of Connecticut School of Medicine, Farmington, Connecticut, United States of America. Send correspondence to: Thomas F. Babor, University of Connecticut School of Medicine, 263 Farmington Avenue, Farmington, Connecticut 06030-6325, United States of America; telephone: (860) 679-5481; fax: (860) 679-5463; e-mail: babor@ nso.uchc.edu

2 University of Texas School of Public Health, Dallas Regional Campus, Dallas, Texas, United States of America.
Alcohol policy is broadly defined as any purposeful effort on the part of governments or nongovernment groups to minimize or prevent alcoholrelated consequences. Policies can involve the implementation of a specific strategy with regard to alcohol problems (e.g., age restrictions on al- cohol sales) or the allocation of resources that reflect priorities with regard to prevention or treatment intervention efforts. Among the various strategies and interventions that have been used as a basis for alcohol policy are: taxation and pricing, regulating the physical availability of alcohol, 
modifying the drinking context, countermeasures to deal with driving while intoxicated, regulating alcohol promotion, education and persuasion strategies, and treatment and early intervention services $(1,2)$. In recent years there has been an increasing interest in alcohol policy in the Americas, in part because of the growing concern over the burden of disease and disability connected to alcohol, and in part because of the increasing quality and quantity of the policyrelevant research that has been produced. In this article we review the evidence base for effective alcohol policy, giving special attention to the implications for policy initiatives in the Americas. Although much of this literature has been reviewed in recent integrative reviews and policy documents (1-3), there is a need to adapt alcohol policy to fit the epidemiological and socioeconomic profiles of different countries and cultures. To that end, this paper begins with a brief review of epidemiological surveys of the prevalence of alcohol problems in the Americas. This is followed by an analysis of prevention strategies and interventions in terms of the evidence for their effectiveness, amount of research support, cost to implement, and other feasibility issues. Finally, the implications of the evidence are discussed for alcohol policy initiatives in the Americas, based on an analysis of the extent to which strategies and interventions currently used in 25 countries are likely to have an impact on alcohol-related problems.

\section{ALCOHOL EPIDEMIOLOGY AND ITS ROLE IN POLICY DEVELOPMENT}

Epidemiology plays an important role in a systematic approach to alcohol control policies. Epidemiological methods make it possible to assess alcohol use and the magnitude of alcohol-related problems across countries and over time through such population measures as per capita consumption, extent of heavy episodic drinking, and the prevalence of alco- hol abuse, alcohol dependence, and alcohol-related problems.

According to Rehm and Monteiro (4), there is wide variation in alcohol consumption, alcohol-related problems, and the burden of disease and disability attributable to alcohol throughout the Region of the Americas. The evidence $(1,4)$ shows that, overall, about two-thirds of the males and a little more than half of the females 15 years of age and older are drinkers (i.e., people who have had at least one drink of an alcoholic beverage during the previous 12 months or another specified period). On average, per capita alcohol consumption in the Americas is more than $50 \%$ above the global consumption level. Because countries such as Brazil, Chile, and Mexico have a relatively high proportion of abstainers, per capita consumption for drinkers is considerably higher than per capita consumption for the population as a whole. This is important because, in general, the higher the per capita consumption in a population, the higher the prevalence of alcohol-related problems (1).

The term "drinking patterns" refers to the amount and variability of alcohol consumption. Of importance are those drinking patterns in which a large number of drinks are consumed in a relatively short period of time (say, five or more drinks in two hours). This type of heavy episodic drinking leads to psychomotor impairment through intoxication, and it has been closely associated with a variety of harms, especially injuries and trauma. In general, the countries of Central and South America have a drinking pattern characterized by high alcohol intake per occasion, fiesta drinking, drinking in public places, and not drinking with meals $(1,4)$. This pattern is epitomized by fiesta drinking, which occurs in conjunction with major holidays such as the Carnival celebrations in Brazil and Trinidad and Tobago.

Alcohol consumption causes a considerable disease burden in the Americas: $4.8 \%$ of all the deaths and $9.7 \%$ of all disability-adjusted life years in the year 2000 could be attributed to alco- hol consumption, with most of the burden in Central and South America (4). Intentional and unintentional injuries account for about $60 \%$ of all alcohol-related deaths and almost $40 \%$ of alcohol-related disease burden. Alcohol is the most important of 27 risk factors for death and disability comparatively assessed in the Americas by the World Health Organization (WHO), followed by tobacco $(4,5)$. Based on this evidence, Rehm and Monteiro (4) suggest that interventions should be implemented in the Americas to reduce alcohol-related disability, giving special attention to the prevention of traffic injuries. In addition, adequate treatment for alcohol dependence should play an important role in a comprehensive plan to reduce the alcohol-related burden.

To summarize, epidemiological indicators provide public health officials with valuable information about the types of problems that must be addressed by alcohol policies, and the indicators also help to identify the population groups at high risk. To the extent that these problems vary in prevalence across groups in different locations, different polices may be selected for implementation by local or national governments or by Regional health authorities such as the Pan American Health Organization. As policies are implemented, continued monitoring of these epidemiological indicators makes it possible to tailor interventions to the needs of each country, and to evaluate policy effectiveness.

\section{EVIDENCE-BASED STRATEGIES AND INTERVENTIONS}

Recent integrative literature reviews and policy analyses provide a comprehensive evaluation of strategies and interventions used by local and national governments in the control or amelioration of alcohol-related problems throughout the world (1-3). Table 1 summarizes the results of an expert consensus panel that rated 32 alcohol policy options in terms of evidence of effectiveness, breadth of research support, and cross-cultural 
generalizability (1). The results indicate that there are a variety of effective policy options that can be used to guide alcohol policy, but some popular strategies (e.g., alcohol education in schools) have little or no empirical support, whereas some unpopular options (e.g., alcohol taxes) have good supporting evidence. In this section, we summarize the evidence for various strategies in the seven policy areas listed in Table 1.

\section{Pricing and taxation}

As with other commodities, the consumption of alcoholic beverages responds to price. In general, alcohol consumption rises when prices are lowered, and it falls when prices are increased. This is true even for heavy drinkers and alcoholics, whose dependence on alcohol is commonly thought to make them less responsive to economic disincentives (6). That is, it is often assumed that alcoholics and heavy drinkers "will drink anyway," regardless of how much it costs. Nevertheless, the evidence shows that those persons modify the amount that they drink in ways similar to ways that nonalcoholic drinkers do when they are affected by taxes on and the price of alcoholic beverages (6). In addition, economic studies demonstrate that increased alcoholic beverage taxes and higher prices are related to reductions in alcohol-related problems (7). Tax increases have been shown to affect rates of cirrhosis mortality, alcohol-related traffic fatalities, and violent crime (1). Because taxes can be used both to generate direct revenue and to reduce alcohol-related harm, public health authorities consider taxes to be an attractive instrument of alcohol policy (3).

However, the effectiveness of alcohol taxes in reducing alcohol-related problems can be neutralized to some extent by increases in smuggling and illegal alcohol production. In some countries of South America (e.g., Brazil), government control is exercised only over certain portions of the alcohol market because of illicit home production. As much as $60 \%$ of the alcohol production in Brazil and some other developing countries may go unrecorded (1). The establishment of efficient mechanisms to control the market and to collect taxes is an important public health priority if taxation is to be used as an instrument of alcohol policy.

\section{Regulating the physical availability of alcohol}

The physical availability of alcohol refers to the accessibility or convenience of obtaining and consuming alcoholic beverages. Research demonstrates that reductions in the hours and days of sale, controls on the number of alcohol outlets, and restrictions on access to alcohol are associated with reductions in both alcohol use and alcohol-related problems $(1,8,9)$. A related strategy is the promotion of alcohol-free environments at such places as sports arenas or work settings. The evidence also suggests that making beverages of low alcohol content (e.g., 3\% alcohol or less) more available than are higher-strength beverages may also be effective in reducing overall alcohol consumption and problems (10).

Laws that raise the minimum legal purchasing age reduce alcohol sales and problems among young drinkers (11). Regulations directed at commercial vendors of alcohol who sell to minors and ignore other restrictions can also be effective (12). However, these regulations need to be supported by a system of specific licenses for selling alcoholic beverages and the power to suspend or revoke a license in the case of sales infractions. A comprehensive alternative method to regulate alcohol availability is through governmentowned retail monopolies. Governmentowned or government-operated retail stores that sell alcoholic beverages for consumption in places other than licensed premises, such as bars and restaurants, can use price and availability controls to limit the amount of alcohol consumed and alcohol-related problems. The evidence also indicates that total alcohol consumption can in- crease, sometimes substantially, when government monopolies are dissolved in favor of for-profit retail licenses (13, 14). This is because governmentowned retail systems generally have fewer outlets, shorter opening hours, and better control of sales to minors and intoxicated persons.

Historical evidence (15) from a number of countries has shown that extreme restrictions on alcohol availability, such as the complete banning of all alcohol sales (i.e., total prohibition), reduces drinking and alcohol-related problems, at least in the short run. These restrictions, however, often have adverse side effects, such as illicit production and sales (2). In many cases these negative effects are more visible than the positive gains in public health, which makes prohibition a risky policy unless there is widespread public support for it, such as in parts of India or in the Islamic countries. In general, however, the cost of restricting physical availability of alcohol is inexpensive relative to the costs of health consequences related to heavy drinking.

\section{Modifying the drinking context}

Many prevention strategies attempt to limit the amount of drinking in the environments where alcohol is typically sold and consumed such as bars and restaurants. The most effective options involve the enforcement of serving regulations and measures making bar staff and owners legally liable for the actions of intoxicated patrons (1, 3). One approach, called responsible beverage service (RBS) training, focuses on the attitudes, knowledge, skills, and practices of persons who serve alcoholic beverages on licensed premises (16). ("Licensed premises" are bars, restaurants, and other establishments that are given a legal permit from the governing authority for the retail sale and consumption of alcoholic beverages). RBS training can reduce heavy consumption and highrisk drinking if supported by actual changes in the serving policies of licensed establishments and reinforced by local police $(17,18)$. 
TABLE 1. Expert ratings of policy-relevant strategies and interventions used throughout the world to prevent or minimize alcohol-related problems $^{\mathrm{a}}$

\begin{tabular}{|c|c|c|c|}
\hline Strategy/Intervention & $\begin{array}{l}\text { Overall } \\
\text { effectiveness }^{\mathrm{b}}\end{array}$ & $\begin{array}{l}\text { Cost to } \\
\text { implement } \\
\text { and sustain }\end{array}$ & Comments \\
\hline Total ban on sales & +++ & High & $\begin{array}{l}\text { Substantial adverse side effects from black market, which is expensive to } \\
\text { suppress. Ineffective without enforcement. }\end{array}$ \\
\hline Minimum legal purchase age & +++ & Low & $\begin{array}{l}\text { Reduces hazardous drinking, but does not eliminate drinking. Effective with } \\
\text { minimal enforcement, but enforcement substantially increases effectiveness. }\end{array}$ \\
\hline Government monopoly of retail sales & +++ & Low & Effective only if operated with public health and public order goals. \\
\hline Restrictions on hours and days of sale & ++ & Low & Effective in certain circumstances. \\
\hline Restrictions on density of outlets & ++ & Low & $\begin{array}{l}\text { Requires a longer time course for implementation when drinking establishments } \\
\text { have become concentrated because of vested economic interests. }\end{array}$ \\
\hline \multicolumn{4}{|l|}{ Taxation } \\
\hline Alcohol taxes & +++ & Low & $\begin{array}{l}\text { Effectiveness depends on government oversight and control of alcohol produc- } \\
\text { tion and distribution. High taxes can increase smuggling and illicit production. }\end{array}$ \\
\hline \multicolumn{4}{|l|}{ Altering the drinking context } \\
\hline Policy to not serve intoxicated patrons & + & Moderate & Training alone is insufficient. Outside enforcement essential to effectiveness. \\
\hline $\begin{array}{l}\text { Training bar staff and managers to } \\
\text { prevent and better manage aggression }\end{array}$ & + & Moderate & Effectiveness depends on continued monitoring of critical incidents \\
\hline Voluntary codes of bar practice & 0 & Low & Ineffective without enforcement. \\
\hline $\begin{array}{l}\text { Enforcement of serving and sales } \\
\text { regulations at bars and restaurants }\end{array}$ & ++ & High & Compliance depends on perceived likelihood of enforcement. \\
\hline College student education & 0 & High & May increase knowledge and change attitudes but has no effect on drinking. \\
\hline Public service announcements (PSAs) & 0 & Moderate & $\begin{array}{l}\text { Responsible drinking messages do not deter heavy drinkers; messages to } \\
\text { strengthen public support for effective policies may be more fruitful. }\end{array}$ \\
\hline Warning labels & 0 & Low & Raise awareness, but do not change behavior. \\
\hline \multicolumn{4}{|l|}{ Regulating alcohol promotion } \\
\hline Advertising bans & $+^{\mathrm{d}}$ & Low & $\begin{array}{l}\text { Strongly opposed by alcoholic beverage industry; can be circumvented by } \\
\text { product placements on TV and in movies. }\end{array}$ \\
\hline Advertising content controls & $?$ & Moderate & $\begin{array}{l}\text { Often subject to industry self-regulation agreements, which are rarely enforced } \\
\text { or monitored. }\end{array}$ \\
\hline \multicolumn{4}{|l|}{ Drink-driving countermeasures } \\
\hline Sobriety checkpoints & ++ & Moderate & Effects of police campaigns typically short-term. \\
\hline Random breath testing & ++ & Moderate & $\begin{array}{l}\text { Somewhat expensive to implement. Effectiveness depends on number of } \\
\text { drivers directly affected. }\end{array}$ \\
\hline $\begin{array}{l}\text { Lowered blood alcohol concentration } \\
\text { limits }\end{array}$ & +++ & Low & Diminishing returns at lower levels (e.g. $0.05 \%-0.02 \%$ ), but still significant. \\
\hline
\end{tabular}


TABLE 1. (Continued)

\begin{tabular}{|c|c|c|c|}
\hline Strategy/Intervention & $\begin{array}{l}\text { Overall } \\
\text { effectiveness }^{b}\end{array}$ & $\begin{array}{l}\text { Cost to } \\
\text { implement } \\
\text { and sustain }\end{array}$ & Comments \\
\hline $\begin{array}{l}\text { Low blood alcohol concentration for } \\
\text { young drivers ("zero tolerance") }\end{array}$ & ++ & Low & Evidence for effectiveness comes mainly from Australia and the United States. \\
\hline Designated drivers and ride services & 0 & Moderate & $\begin{array}{l}\text { May increase awareness of risk and deter small numbers of drunk drivers but } \\
\text { have no overall impact on traffic accidents. }\end{array}$ \\
\hline \multicolumn{4}{|l|}{ Treatment and early intervention } \\
\hline Brief intervention with at-risk drinkers & ++ & Moderate & $\begin{array}{l}\text { Primary care practitioners lack training and time to conduct screening and brief } \\
\text { interventions. }\end{array}$ \\
\hline $\begin{array}{l}\text { Mandatory treatment of repeat } \\
\text { offenders who drive while intoxicated }\end{array}$ & + & Moderate & $\begin{array}{l}\text { Punitive and coercive approaches have time-limited effects, and they } \\
\text { sometimes distract attention from more effective interventions. }\end{array}$ \\
\hline
\end{tabular}

adapted from Babor et al. (1), who were also responsible for the expert ratings.

${ }^{b}$ Overall effectiveness represents a summary of three evaluative ratings made by Babor et al. (1). The three were: (1) the extent to which the scientific evidence supports the effectiveness of a particularly intervention; (2) breadth of research support, i.e., the quantity and consistency of the evidence; and (3) the extent to which the evidence applies equally well to different countries, cultural groups, and social classes. The ratings were made according to the following scale: $0=$ evidence indicates a lack of effectiveness; $+=$ evidence for limited effectiveness; ++ = evidence for moderate effectiveness; +++ = evidence of a high degree of effectiveness; ? = no studies have been undertaken, or there is insufficient evidence upon which to make a judgment.

${ }^{c}$ Refers to the monetary and other costs associated with an intervention, regardless of its effectiveness.

${ }^{d}$ Econometric studies find effects of advertising bans, but direct studies of short-term impacts have generally found no effect on total alcohol consumption.

A more comprehensive approach supported by research is community mobilization, which has been used to raise public awareness of problems associated with drinking in licensed establishments (e.g., violence, driving after drinking), to develop specific solutions to local problems, and to pressure owners to recognize that they have a responsibility to the community in terms of such bar-related problems as noise and disruptive behavior (19-21). Community mobilization can reduce aggression and other problems related to drinking in licensed premises, but the long-term sustainability of these efforts has not been demonstrated.

\section{Measures to prevent driving while intoxicated}

A variety of legal measures have been developed to deter driving while intoxicated. The most prominent mea- sures are designed to catch offenders, based on the assumption that a clearly specified, measurable blood alcohol limit will deter people from driving after drinking. Other measures include punishments for being convicted of driving while intoxicated. In recent years emphasis has been placed not only on catching and punishing drinking drivers but also on deterring drinkers from driving in the first place. Deterrence approaches work best when the chances of being caught are perceived to be high, and the punishment is thought to be swift and certain. Random breath testing (RBT), where motorists are stopped by police and required to take a preliminary breath test, has been found to be the most effective approach $(22,23)$. Highly visible, nonselective testing on a regular basis can have a sustained effect on both driving while intoxicated and the associated crashes, injuries, and deaths (24).
National and state laws lowering the legal limit of the driver's blood alcohol concentration (BAC), when combined with enforcement, have also been shown to reduce driving while intoxicated. Setting a reasonably low BAC level (e.g., $0.05 \%$ ) significantly reduces alcohol-related driving fatalities (22). One way to increase the certainty and swiftness of punishment is through administrative license suspension, where, in the event of a police citation for driving while intoxicated, the driver's license is suspended administratively, without the need for a judicial process $(25,26)$. In addition, evidence from some countries supports the effectiveness of comprehensive treatment, including counseling or therapy plus license suspension, in reducing recidivism (27). Successful programs are well-structured, go beyond information provision, address alcohol abuse, and have court-enforced rules of attendance at Alcoholics Anonymous 
groups, treatment programs, or alcohol education meetings.

Young drivers are at higher risk for alcohol-involved crashes as a result of their limited driving experience and their tendency to experiment with heavy episodic drinking. Traditional countermeasures include driver training and school-based education programs, which are ineffective (1). The most effective measures are ones that raise the minimum age for a driving license, and the use of graduated licensing for novice drivers, which limits the conditions of driving during the first few years of licensing $(1,28)$.

In the United States, threats to withhold federal Government funds that go to the states for highway construction and maintenance have persuaded state legislatures to raise the legal drinking age from 18 to 21 years. As noted above, such age increases considerably reduce alcohol-related traffic fatalities among youth. Such actions might have a similar impact in Brazil and other Latin American countries that have a federal system of government.

\section{Regulating alcohol promotion}

Alcohol brands and products are typically promoted through clearly defined commercial advertisements appearing in a variety of media (e.g., television, radio, print, point-of-sale promotions, and now even the Internet). In addition to these direct forms of advertising, alcohol is marketed indirectly through event sponsorship and through product placements in movies and TV shows. Exposure to constant high levels of alcohol promotion can establish attitudes favorable to drinking. Alcohol advertising may predispose minors to drinking well before the legal age of purchase and reinforce the perception that drinking is positive, glamorous, and relatively risk-free $(1,29)$. Many countries have partial restrictions on alcohol advertising, and some have total bans (30). Although these restrictions do not have a major effect on drinking, countries with the greatest restrictions on advertising tend to have less drinking and fewer alcohol-related problems (31). Despite industry claims that they adhere to codes of responsible advertising, the detrimental influences of marketing practices are not adequately addressed by industry self-regulation. Self-regulation tends to be fragile and largely ineffective in countries where it is the primary way to control alcohol advertising, in part because it is often circumvented and rarely enforced (1).

\section{Education and persuasion strategies}

School-based alcohol education programs have been the method of choice in attempts to prevent alcohol-related problems among young adults. Schoolbased alcohol education programs have been found to increase knowledge and change attitudes toward alcohol, but they are not an effective means to change drinking behavior $(32,33)$. Beyond the provision of information about alcohol's negative effects, programs that address "values clarification," self-esteem, general social skills, and activities intended to replace alcohol use (e.g., sports) are equally ineffective (34). Modest changes in drinking have been associated with resistance skills training (classroom exercises to teach students how to resist peer pressure to consume alcohol) and with normative education (which attempts to correct adolescents' tendency to overestimate the number of their peers who drink), but the effects disappear after the programs are concluded $(35,36)$. Comprehensive programs that include both education and community-level interventions may be equally inadequate in delaying the initiation of drinking, or in sustaining a reduction in drinking beyond the operation of the program (36).

Public service announcements (PSAs) that discourage alcohol misuse and driving while intoxicated are prepared by nongovernmental organizations, health agencies, and the advertising industry. Despite the good intentions, these messages have not been found to be effective in changing drinking behavior or preventing alcohol-related problems, perhaps because they can- not compete effectively with the highquality pro-drinking messages that appear much more frequently as paid advertisements in the mass media (1). Similarly, health-warning labels on product packaging, such as messages explaining that consuming alcohol during pregnancy may cause birth defects, produce no change in drinking behavior $(37,38)$ despite the fact that a significant proportion of the population reports seeing the warnings.

In sum, the impact of education and persuasion programs tends to be small at best. When positive effects are found, they do not persist.

\section{Treatment and early intervention services}

The development of specialized treatment programs for alcoholics has become an accepted way for governments and for nongovernmental organizations to help problem drinkers. Participation in almost any kind of treatment is associated with significant reductions in alcohol use and related problems, regardless of the type of intervention used (3). There are many different therapeutic approaches to choose from. The weight of evidence suggests that behavioral treatments (which teach relapse prevention skills) are more effective than insight-oriented therapies (which explore psychological conflicts and the underlying causes of excessive drinking) (39).

In addition to therapies based on counseling, behavioral skills training, and motivational enhancement, several new pharmacological compounds have been developed to address the neurobiological basis of alcohol dependence (3). Naltrexone, an opioid antagonist, and acamprosate, an amino acid derivative, have been shown to be effective in the prevention of relapse (40, 41). However, these pharmacological interventions should be viewed as an adjunct to outpatient therapy rather than stand-alone treatments.

Although mutual help societies, such as Alcoholics Anonymous (AA), are not considered to be formal treatment, they are often used as inex- 
pensive substitutes, alternatives, and adjuncts to treatment (42). Research suggests that AA itself can have an incremental effect when combined with formal treatment, and that AA participation alone may be as effective as formal treatment is (43-45).

In contrast to treatment provided to alcoholics in specialized settings, brief interventions consist of one to three sessions of counseling or advice delivered in general medical settings to nonalcoholic heavy drinkers. Numerous randomized controlled trials indicate that clinically significant changes in drinking behavior and related problems can follow from brief interventions $(46,47)$. In Brazil, for instance, brief interventions have proved to be effective, although studies have focused on mixed samples of alcoholand drug-dependent clients (48-50).

When treatment and early intervention are available to large segments of the population, there is some evidence that these services can reduce the rates of alcohol problems in a society (51, 52). Nevertheless, specialized services (other than mutual help organizations) tend to be expensive and may not be cost-effective in developing countries unless they are integrated with the primary care system.

\section{Summary of evidence-based strategies and interventions}

Building on previous work in this area, Babor et al. (1) rated 32 policy options, classified under the seven major policy areas reviewed above, according to four major criteria: (1) evidence of effectiveness, (2) strength of research support, (3) extent of testing across diverse countries and cultures, and (4) relative cost in terms of time, resources, and money. Table 1 summarizes the consensus ratings of these various policy options in terms of their overall effectiveness (the first three criteria) and relative cost to implement and sustain them.

According to Table 1, the following 10 policy options stand out as "best practices" because of their overall effectiveness and relatively low cost to implement and sustain: minimum age to legally purchase alcohol, government monopoly on retail sales, restrictions on hours or days of sale, restrictions on the density of sales outlets, alcohol taxes, random breath testing of drivers, lowered BAC limits for drivers, administrative license suspension for driving while intoxicated, graduated licensing for novice drivers, and brief interventions for problem drinkers.

\section{IMPLICATIONS FOR ALCOHOL POLICY IN THE AMERICAS}

Alcohol policy priorities should be informed by the epidemiological data as well as by the scientific evidence on which prevention strategies and interventions are effective. Designing effective alcohol policies for a nation or for a community should start from an assessment of the policy responses that are already in place. These policy responses should be evaluated in terms of their appropriateness to the local situation and the extent to which they are consistent with the scientific evidence. To that end, we authors evaluated alcohol policies for 25 countries in the Americas, drawing on data from an extensive WHO survey (30). Key informants in each country provided information about the nature and enforcement of selected alcohol policies. The policies described in the WHO survey were chosen because of the availability of reporting information and the relevance of the policy option to the prevention of alcohol-related problems.

Based on the country-level information provided in the WHO survey, we selected six policy areas that could be scored in terms of the effectiveness criteria described in Table 1 . The scores were designed to reflect the expected impact of a particular policy on the extent of alcohol-related problems from a public health perspective. For example, key informants in the 25 countries were asked about the policies governing the control of alcoholic beverage sales at retail outlets. From the overall effectiveness ratings summarized in Table 1, we assumed that monopoly systems would be the most effective type of control, followed by the license system. These two approaches were given scores of 3 and 2, respectively. Countries reporting minimal controls or no controls, which are considered the least effective policies, were scored 1 and 0 , respectively. Similarly, answers to questions in the WHO survey about advertising restrictions allowed us to determine whether a given country had no restrictions, minimal restrictions, partial restrictions, or total advertising bans. This information was used to assign scores ranging from 0 (no restrictions) to 3 (total bans), reflecting the likely public health impact of a country's policies regarding alcohol advertising.

As shown in Table 2, these data are compiled in a way that makes it possible to evaluate whether a given country's alcohol policies can be expected to have a public health impact, based on the scientific evidence summarized in Table 1. The higher the score (range, $0-3)$, the more the intervention or strategy is likely to have an impact. Because data were sometimes lacking on the extent to which these policies are implemented and enforced, it is not possible to say whether the policies actually are effective in a given country. Nevertheless, the table does provide a way to evaluate the potential impact of a country's policies, and to compare one country with another. As such, the ratings constitute a "report card" for each country in terms of key alcohol policies. The six areas evaluated are: retail sales controls, availability restrictions, age limits on alcohol purchases, the relative price of alcohol, advertising restrictions, and countermeasures against driving while intoxicated (BAC limits and use of random breath testing). The last column in Table 2 provides a summary indicator that reflects the overall likelihood that a country's alcohol policies will have an impact on alcohol-related problems if the policies are properly implemented and enforced. To the extent that individual policy ratings in a given country fall short of the optimal score of 3 points, the data indicate where policy changes would most 
TABLE 2. Estimated impact scores for alcohol-policy strategies and interventions currently used in 25 countries in the Americas ${ }^{a}$

\begin{tabular}{|c|c|c|c|c|c|c|c|c|}
\hline \multirow[b]{2}{*}{ Country } & \multirow{2}{*}{$\begin{array}{c}\text { Retail } \\
\text { controls }^{b}\end{array}$} & \multirow{2}{*}{$\begin{array}{l}\text { Availability } \\
\text { restrictions }^{\mathrm{C}}\end{array}$} & \multirow{2}{*}{$\begin{array}{l}\text { Age } \\
\text { limits }^{d}\end{array}$} & \multirow{2}{*}{$\begin{array}{l}\text { Relative } \\
\text { price }^{\mathrm{e}}\end{array}$} & \multirow{2}{*}{$\begin{array}{l}\text { Advertising } \\
\text { restrictions }^{f}\end{array}$} & \multicolumn{2}{|c|}{$\begin{array}{l}\text { Driving while } \\
\text { intoxicated }\end{array}$} & \multirow{2}{*}{$\begin{array}{l}\text { Mean } \\
\text { ratingi }\end{array}$} \\
\hline & & & & & & BACg & $\mathrm{RBT}^{\mathrm{h}}$ & \\
\hline Belize & 2 & 1 & 2 & 1 & 2 & 2 & 0 & 1.43 \\
\hline Bolivia & 2 & 1 & 2 & 3 & 2 & 2 & 1 & 1.86 \\
\hline Brazil & 0 & 0 & 2 & 1 & 1 & 2 & 0 & 0.86 \\
\hline Canada & & & & & & & & \\
\hline Colombia & 3 & 2 & 2 & 2 & 2 & 3 & 3 & 2.43 \\
\hline Costa Rica & 3 & 3 & 2 & 2 & 2 & 3 & 2 & 2.43 \\
\hline Dominican Republic & 2 & 1 & 2 & $N A^{j}$ & 2 & 1 & 0 & 1.57 \\
\hline Ecuador & 2 & 2 & 2 & NA & 2 & 2 & 1 & 1.86 \\
\hline El Salvador & 3 & 2 & 2 & NA & 1 & 3 & 3 & 2.29 \\
\hline Guatemala & 2 & 1 & 2 & 3 & 2 & 2 & 2 & 2.00 \\
\hline Nicaragua & 2 & 1 & 2 & 3 & 1 & 2 & 1 & 1.71 \\
\hline Panama & 2 & 2 & 2 & 2 & 2 & 3 & 0 & 1.86 \\
\hline Paraguay & 2 & 2 & 2 & 2 & 2 & 2 & 2 & 2.00 \\
\hline Peru & 2 & 1 & 2 & 2 & 1 & 3 & 2 & 1.86 \\
\hline Suriname & 2 & 1 & 1 & 2 & 0 & 2 & 0 & 1.14 \\
\hline Trinidad and Tobago & 1 & 2 & 2 & 2 & 0 & 0 & 0 & 1.00 \\
\hline \multicolumn{9}{|l|}{ United States } \\
\hline (state of California) & 2 & 2 & 3 & 1 & 1 & 2 & 0 & 1.57 \\
\hline Uruguay & 2 & 1 & 2 & 1 & 0 & 2 & 1 & 1.29 \\
\hline Venezuela & 2 & 2 & 2 & 2 & 3 & 3 & 2 & 2.29 \\
\hline Mean Policy Rating & 1.9 & 1.6 & 2.0 & 1.9 & 1.4 & 2.2 & 1.2 & \\
\hline
\end{tabular}

a Adapted from World Health Organization survey data (30).

b The "retail controls" score is based on our interpretation of survey responses obtained by WHO (30) from key informants (e.g., national health ministers) who answered questions about control of retail sale and production: $0=$ no controls; $1=$ minimal controls; 2 = license system for beer, wine, and spirits; $3=$ monopoly system or mixed monopoly/license controls. The higher the score, the greater the public health impact estimated by the authors.

"The "availability restrictions" score is based on our interpretation of survey responses obtained by WHO (30) from key informants (e.g., national health ministers), who answered questions about retail outlets such as bars and restaurants. The score was for sales restrictions and overall level of enforcement for hours of sale, days of sale, places of sale, and density of outlets: 1 = poor; 2 = good; 3 = excellent.

${ }^{d}$ The "age limits" score is based on our interpretation of survey responses obtained by WHO (30) from key informants (e.g., health ministers) to questions about age limits for purchasing alcoholic beverages: $0=$ no limits; 1 = age 16-17; 2 = age 18-20; $3=$ age 21+

e The "relative price" score is based on information obtained by the WHO and reported in Table 19 of the Global Status Report: Alcohol Policy (30). For each of the 25 countries of the Americas we authors aggregated the relative prices of alcoholic beverages across beer, wine, and spirits. The summary measure was then divided into three levels: $1=$ among lower third of reporting WHO Member States in world; 2 = among middle third of reporting WHO Member States in the world; 3 = among highest third of reporting WHO Member States in the world.

' The "advertising restrictions" score is based on survey responses obtained from a WHO survey (30) of key informants (e.g., health ministers) who answered questions about restrictions on advertising appearing on national television, national radio, print media, and billboards; it is also based on key informants' estimates of enforcement of advertising and sponsorship restrictions. The scores were: $0=$ no restrictions; 1 = minimal restrictions; $2=$ partial restrictions; $3=$ total advertising ban on television and/or other media.

${ }^{9}$ This blood alcohol concentration (BAC) score is based on survey data obtained by WHO (30) from key informants' reports of the maximum BAC level used to enforce laws pertaining to driving while intoxicated: $0=$ no BAC limit; $1=0.10 \%$ or higher; $2=0.06 \%-0.09 \% ; 3=0.05 \%$ or lower.

$\mathrm{h}$ This random breath testing (RBT) score is based on survey responses obtained by WHO (30) from key informants to questions about the use of random breath testing to enforce laws pertaining to driving while intoxicated: $0=$ no RBT; $1=$ rarely; $2=$ sometimes; $3=$ often

Mean rating is across all interventions and strategies.

$\mathrm{NA}=$ data not available.

likely have a positive impact on public health. The bottom row of the table provides the mean of the policy scores across the countries for each strategy or intervention.

As shown in the last column of Table 2, the countries that have adopted the highest-impact policies overall are Colombia (2.57), Costa Rica (2.57),
Venezuela (2.29), and El Salvador (2.29). The countries most in need of improvement are Brazil (0.86), Tobago and Trinidad (1.00), Suriname (1.14), and Uruguay (1.29). As shown in the averages in the last row of the table, policy areas with the highest expected impact across all countries are BAC level (2.2), age limits (2.0), retail con- trols (1.9), and relative price of alcohol (1.9). The relative price is in part dependent on government tax policies, which are more likely to reduce alcohol problems when alcohol is taxed at a higher level in order to reduce demand. Policy areas scored as having the least likelihood of impact because of the general failure to use optimally 
effective measures are driving while intoxicated countermeasures (i.e., random breath testing (1.2)), advertising restrictions (1.4), and restrictions on availability (1.6).

Based on the impact scores, it is clear that almost all the countries listed in Table 2 could improve the likelihood of preventing alcoholrelated problems. For example, most countries in the Americas have moderate $(0.06 \%-0.09 \%)$ to low $(0.05 \%$ or lower) BAC levels to define driving while intoxicated, but these limits are not likely to be effective without consistent enforcement. Random breath testing is an effective way to prevent alcohol-related automobile accidents and injuries. However, most countries in the Americas lack the resources or expertise to conduct RBT. Similarly, most countries in the Americas have the capacity to impose taxes on the production and sale of alcoholic beverages, but the relative price of alcohol in many of these countries is low in comparison to other countries in the world, where alcohol is considerably more expensive (30). Advertising restrictions are another area where alcohol controls are relatively weak throughout the Americas. Six of the 25 countries reported no controls on alcohol advertising, and 5 others reported minimal restrictions governing the marketing of alcohol on television, radio, print media, and billboards. Only one country (Venezuela) bans alcohol advertising entirely on television and radio, but even here only partial restrictions apply to print media and billboards. Although age limits on the purchase of alcoholic beverages are specified in all countries, two countries (Jamaica and Suriname) allow purchases by those 16-17 years old, and almost all of the others allow alcohol purchases by those 18-20 years old. Only one country in the Americas, the United States, imposes an age limit (21 years) that has been shown to be effective in the prevention of alcoholrelated traffic accidents, although it should be pointed out that age limits have not been evaluated in other parts of the Americas. Finally, few countries listed in Table 2 report optimal controls on retail sales of alcoholic beverages, suggesting that there are ample opportunities for improvement in this very effective method of alcohol control policy.

\section{Conclusion}

Unintentional injuries stand out as the most significant disease category contributing to the alcohol-related burden in the developing countries of Central and South America. Efforts in the policy-making area should therefore strive to reduce the load of this burden category, using such strategies as countermeasures against driving while intoxicated, programs that alter the drinking context, and limits on physical availability. Given the relatively high per capita consumption levels in many of the Latin American countries, policies to reduce average volume of drinking should also be implemented. This could perhaps be done through a strategy that combines early intervention for problem drinkers in health care settings and cost-effective interventions such as taxation or availability restrictions.
For the developed, high-income countries in North America, the goal should be to prevent deterioration of the current drinking patterns and to reduce the overall volume of drinking. Early intervention seems promising, since most of the alcohol-related burden in these countries is linked to alcoholuse disorders, which can be detected in primary care and emergency departments. In addition, measures that reduce per capita consumption should be implemented, such as higher alcohol taxes and stricter limits on alcohol availability. And given the high prevalence of heavy episodic drinking among young adults, policies directed at underage drinking and driving while intoxicated should also be strengthened.

It is clear that many evidence-based policies are capable of reducing the burden of disease and disability associated with alcohol consumption. Two things are lacking to address alcohol problems from a public health perspective: (1) a convincing and coherent rationale to guide the policy-making process, and (2) the resources to implement and sustain high-impact alcohol policies. Given the low to moderate cost of many of the evidence-based policies reviewed in this article, it now seems possible for communities and nations in the Americas to substantially reduce the alcohol-related burden of illness.

Acknowledgement. The writing of this paper was supported in part by a grant from the United States National Institute on Alcohol Abuse and Alcoholism (1R21 AA014635 Evaluating Alcohol Brief Intervention Implementation).

\section{REFERENCES}

1. Babor T, Caetano R, Casswell S, Edwards G, Giesbrecht N, Graham K, et al. Alcohol: no ordinary commodity: research and public policy. Oxford: Oxford University Press; 2003.

2. Room R, Jernigan D, Carlini-Marlatt B, Gureje $\mathrm{O}$, Mäkelä K, Marshall M, et al. Alcohol in developing societies: a public health approach. Helsinki: Finnish Foundation for Alcohol Studies; 2002.
3. Room R, Babor T, Rehm J. Alcohol and public health. Lancet. 2005;365:519-30.

4. Rehm J, Monteiro M. Alcohol consumption and burden of disease in the Americas: implications for alcohol policy. Rev Panam Salud Publica. 2005;18(4/5):241-8.

5. Rehm J, Room R, Monteiro M, Gmel G, Graham K, Rehn N, et al. Alcohol use. In: World Health Organization. Comparative quanti- fication of health risks: global and regional burden of disease due to selected major risk factors [CD-ROM]. Geneva: WHO; 2003. Pp. 959-1108. 6. Babor TF. Alcohol, economics and the ecological fallacy: toward an integration of experimental and quasi-experimental research. In: Single E, Storm T, eds. Public drinking and public policy. Toronto: Addiction Research Foundation; 1985. Pp. 161-89. 
7. Chaloupka FJ, Grossman M, Saffer H. The effects of price on alcohol consumption and alcohol-related problems. Alcohol Res Health. 2002;26:22-34

8. Gruenewald PJ, Millar AB, Roeper P. Access to alcohol: geography and prevention for local communities. Alcohol Health Res World. 1996;20:244-51.

9. Pacific Institute for Research and Evaluation. Prevenção de homicídios em Diadema, Brasil: a influência de novas políticas do álcool. Calverton: PIRE; 2004.

10. Skog OJ. Effect of introducing a new light beer in Norway: substitution or addition? Br J Addict.1988;83:665-8.

11. Wagenaar AC, Gehan JP, Jones-Webb R, Wolfson M, Toomey TL, Forster JL, et al. Communities mobilizing for change on alcohol: experiences and outcomes from a randomized community trial. Minneapolis: University of Minnesota; 1998.

12. Wagenaar AC, Wolfson M. Deterring sales and provision of alcohol to minors: a study of enforcement in 295 counties in four states. Public Health Rep. 1995;110:419-27.

13. Wagenaar AC, Holder HD. Changes in alcohol consumption resulting from the elimination of retail wine monopolies: results from five U.S. states. J Stud Alcohol. 1995;56:566-72.

14. Her M, Giesbrecht N, Room R, Rehm J. Privatizing alcohol sales and alcohol consumption: evidence and implications. Addiction. 1999; 94:1125-39.

15. Levine HG. The birth of American alcohol control: prohibition, the power elite, and the problem of lawlessness. Contemp Drug Probl. 1985;12:63-115.

16. Toomey TL, Kilian GR, Gehan JP, Perry CL, Jones-Webb R, Wagenaar AC. Qualitative assessment of training programs for alcohol servers and establishment managers. Public Health Rep. 1998;113:162-9.

17. Howard-Pitney B, Johnson MD, Altman DG, Hopkins R, Hammond N. Responsible alcohol service: a study of server, manager, and environmental impact. Am J Public Health. 1991;81:197-9.

18. Lang E, Stockwell T, Rydon P, Beel A. Can training bar staff in responsible serving practices reduce alcohol-related harm? Drug Alcohol Rev. 1998;17:39-50.

19. Hauritz M, Homel R, Mcllwain G, Burrows T, Townsley M. Reducing violence in licensed venues through community safety action projects: the Queensland experience. Contemp Drug Probl. 1998;25:511-51.

20. Homel R, Tomsen S, Thommeny J. Public drinking and violence: not just an alcohol problem. J Drug Issues. 1992;22:679-97.

21. Putnam SL, Rockett IRH, Campbell MK. Methodological issues in community-based alcohol-related injury prevention projects: attribution of program effects. In: Greenfield TK, Zimmerman R, eds. Experiences with community action projects: new research in the prevention of alcohol and other drug problems. Rockville: Center for Substance Abuse Prevention; 1993. Pp. 31-9.

22. Shults RA, Elder RW, Sleet DA, Nichols JL, Alao MO, Curande-Kulis VG, et al. Reviews of evidence regarding interventions to reduce alcohol-impaired driving. Am J Prev Med. 2001;21:66-88.

23. Henstridge J, Homel R, Mackay P. The longterm effects of random breath testing in four Australian states: a time series analysis. Canberra: Federal Office of Road Safety; 1997.

24. Stewart L, Conway K. Community action to reduce rural drink driving crashes: encouraging sustainable efforts in changing environments. In: Casswell S, Holder H, Holmila M, Larsson S, Midford R, Barnes HM, et al., eds. Fourth Symposium on Community Action Research and the Prevention of Alcohol and Other Drug Problems. Auckland: Alcohol and Public Health Research Unit, University Of Auckland; 1999. Pp. 233-46.

25. McKnight AJ, Voas RB. Prevention of alcoholrelated road crashes. In: Heather N, Peters TJ, Stockwell T, eds. International handbook of alcohol dependence and problems. Chichester: John Wiley and Sons; 2001. Pp. 741-70.

26. Homel R. Penalties and the drink-driver: a study of one thousand offenders. Aust N Z J Criminol. 1981;14:225-41.

27. Wells-Parker E, Bangert-Drowns R, McMillen $\mathrm{R}$, Williams M. Final results from the metaanalysis of remedial interventions with drink/ drive offenders. Addiction. 1995:90:907-26.

28. Ulmer RG, Preusser DF, Williams AF, Ferguson SA, Farmer CM. Effects of Florida's graduated licensing program on the crash rate of teenage drivers. Accid Anal Prev. 2000;32: 527-32.

29. Calfee JE, Scherega C. The influence of advertising on alcohol consumption: a literature review and an econometric analysis of four European nations. Int J Advert. 1994;13:287310.

30. World Health Organization. Global status report: alcohol policy. Geneva: WHO; 2004.

31. Saffer H, Dave D. Alcohol consumption and alcohol advertising bans. Appl Econ. 2002;34: 1325-34.

32. Botvin GJ, Baker E, Dusenbury L, Botvin EM, Diaz T. Long-term follow-up results of a randomized drug abuse prevention trial in a white middle-class population. JAMA. 1995; 273:1106-12.

33. Hansen DJ. Prevention of alcohol use and abuse. Prev Med. 1994;23:683-7.

34. Moskowitz JM. Primary prevention of alcohol problems: a critical review of the research literature. J Stud Alcohol. 1989;50:54-88.

35. Wechsler H, Nelson TF, Lee JE, Seibring M, Lewis C, Keeling RP. Perception and reality: a national evaluation of social norms marketing interventions to reduce college students' heavy alcohol use. J Stud Alcohol. 2003;64: 484-94.

36. Foxcroft DR, Ireland D, Lister-Sharp DJ, Lowe $G$, Breen R. Longer-term primary prevention for alcohol misuse in young people: a systematic review. Addiction. 2003;98:397-411.

37. Grube JW, Nygaard P. Adolescent drinking and alcohol policy. Contemp Drug Probl. 2001;28:87-131.

38. Agostinelli G, Grube J. Alcohol counteradvertising and the media: a review of recent research. Alcohol Res Health. 2002;26:15-21.
39. Longabaugh R, McCrady B, Fink E, Stout R, McAuley T, Doyle C, et al. Cost effectiveness of alcoholism treatment in partial vs. inpatient settings: six-month outcomes. J Stud Alcohol. 1983;44:1049-71.

40. O'Malley SS, Jaffe AJ, Chang G, Schottenfeld RS, Meyer RE, Rounsaville B. Naltrexone and coping skills therapy for alcohol dependence: a controlled study. Arch Gen Psychiatry. 1992; 49:894-8.

41. Kranzler HR, Van Kirk J. Naltrexone and acamprosate in the treatment of alcoholism: a meta-analysis. Alcohol Clin Exp Res. 2001;25: 1335-41.

42. Humphreys K. Circles of recovery: self-help organizations for addictions. Cambridge: Cambridge University Press; 2003.

43. Babor TF, Del Boca FK, eds. Treatment matching in alcoholism. Cambridge: Cambridge University Press; 2002.

44. Ouimette PC, Finney JW, Gima K, Moos RH. A comparative evaluation of substance abuse treatment: examining mechanisms underlying patient-treatment matching hypotheses for 12-step and cognitive-behavioral treatments for substance abuse. Alcohol Clin Exp Res. 1999;23:545-51.

45. Walsh DC, Hingson RW, Merrigan DM, Levenson SM, Cupples LA, Heeren T, et al. A randomized trial of treatment options for alcohol-abusing workers. N Engl J Med. 1991; 325:775-81.

46. Kahan M, Wilson L, Becker L. Effectiveness of physician-based interventions with problem drinkers: a review. Can Med Assoc J. 1995; 152:851-9.

47. Wilk AI, Jensen NM, Havighurst TC. Metaanalysis of randomized control trials addressing brief interventions in heavy alcohol drinkers. J Gen Intern Med. 1997;12:274-83.

48. Formigoni MLOS. A intervenção breve na dependência de drogas : a experiência brasileira. São Paulo: Contexto; 1992.

49. Marques ACPR. Comparação da efetividade da terapia comportamental-cognitiva breve individual e em grupo no tratamento de dependentes de álcool ou outras drogas [thesis]. Universidade Federal de São Paulo; 1997.

50. Marques AC, Formigoni ML. Comparison of individual and group cognitive-behavioral therapy for alcohol and/or drug-dependent patients. Addiction. 2001;96(6):835-46.

51. Smart RG, Mann RE. The impact of programs for high-risk drinkers on population levels of alcohol problems. Addiction. 2000;95:37-52.

52. Kristenson $\mathrm{H}$, Ohlin $\mathrm{H}$, Hulten-Nosslin $\mathrm{M}$, Trell E, Hood B. Identification and intervention of heavy drinkers in middle-aged men: results and follow-up of 24-60 months of long-term study with randomized controls. Alcohol Clin Exp Res. 1983;7:203-9.

Manuscript received 15 September 2004. Revised version accepted for publication 16 June 2005. 
RESUMEN El presente artículo tiene como objetivos describir los datos probatorios en que se deben basar las políticas contra el alcoholismo en las Américas, evaluar en qué medida las políticas nacionales pueden tener un impacto en la salud pública e identificar las

\section{Políticas contra el alcoholismo en las Américas basadas en datos probatorios: aspectos positivos, debilidades y retos futuros}

Palabras clave Consumo de bebidas alcohólicas, intoxicación alcohólica, medicina basada en evidencia, formulación de políticas, Américas.

areas en que estas políticas pueden mejorar. En el artículo se presenta una breve revisión de las encuestas epidemiológicas realizadas para evaluar la prevalencia de los problemas relacionados con el consumo de alcohol en la Región y se analizan 32 esde investigaciones que las respaldan, el costo de su implementación y otros aspectos prácticos. En general, las estrategias e intervenciones con mayor respaldo empírico son los bajos valores de alcoholemia mientras se conduce, los controles sobre el acceso al alcohol, los límites de edad para comprar bebidas alcohólicas y el elevado precio relativo de ellas. Se discuten las implicaciones de los datos en relación con las iniciativas para combatir el alcoholismo en las Américas, según un análisis de la medida en que las políticas e intervenciones empleadas actualmente en 25 países de las Américas pueden tener un impacto sanitario positivo en los problemas relacionados con el consumo de alcohol. Los países que han adoptado las políticas con el mayor impacto esperado son Colombia, Costa Rica, Venezuela y El Salvador. No obstante, el análisis indica que casi todos los países de las Américas podrían mejorar sus posibilidades de evitar problemas relacionados con el alcoholismo. En los países en desarrollo de América Latina, las políticas deben concentrarse en fortalecer las medidas que prohíben conducir en estado de embriaguez, las que modifican el contexto en que se consumen bebidas alcohólicas, y los límites de disponibilidad física. Para los países desarrollados y con altos ingresos de América del Norte, el objetivo debe ser evitar el deterioro de los patrones actuales de consumo y reducir el volumen general de ese consumo. Tomando en cuenta el bajo o moderado costo de muchas de las políticas analizadas en este artículo, es factible que las comunidades y naciones reduzcan notablemente la carga de enfermedades relacionadas con el consumo de bebidas alcohólicas en las Américas. trategias e intervenciones de prevención a la luz de pruebas de su eficacia, el volumen

Prohibir algo es despertar el deseo.

Michel Eyquem de Montaigne,

escritor y pensador francés (1533-1592) 